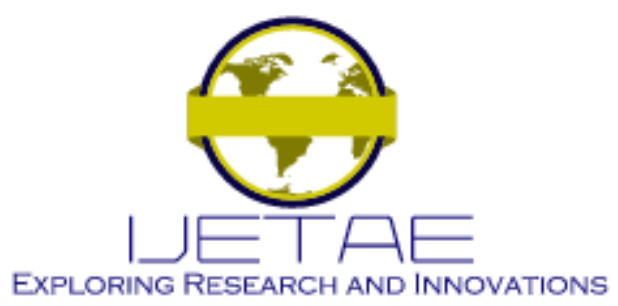

International Journal of Emerging Technology and Advanced Engineering

Website: www.ijetae.com (E-ISSN 2250-2459, Scopus Indexed, ISO 9001:2008 Certified Journal, Volume 11, Issue 08, August 2021)

Manuscript Received: 09 July 2021, Received in Revised form: 08 August 2021, Accepted: 12 August 2021

DOI: $10.46338 /$ ijetae0821_05

\title{
A Study on the Cause Analysis and Solutions of Overdependence on Smartphones in Korean Teenagers
}

\author{
Woochun Jun \\ Dept. of Computer Education, Seoul National University of Education, Seochodong 1650, Seochogu, Seoul, Korea
}

\begin{abstract}
The development of information and communication technology and smart technology in modern society makes daily life very convenient for modern people, while also causing various side effects. These side effects typically appear in various forms, including cyberbullying, Internet addiction, personal information infringement, and the distribution of harmful information. Especially with the development and distribution of smart devices, smartphone overdependence is very serious, especially among teenagers. The purpose of this study is to analyse the causes of overdependence on smartphones in Korean teenagers and also to suggest solutions. The overdependence of smartphones is represented by three phenomena: self-control failure, salience, and serious consequences. A thorough statistical analysis showed that self-control failure was the largest among the three phenomena of overdependence on smartphones, followed by salience and serious consequences. Teenager smartphone over-dependents personally try to solve smartphone overdependence through strengthening smartphone self-control capability and alternative leisure activities. However, both their main and desired leisure activities are smartphone use, and they want other alternative activities, but they cannot escape using smartphones. It is hoped that the results of this study will help follow-up research in the future along with policy directions on teenagers' overdependence on smartphones.
\end{abstract}

Keywords - Smartphone Overdependence, Smartphone Addiction; Teenagers, Information and Communication Technology, Smart Technology, Information Ethics

\section{INTRODUCTION}

Recent advances in computer technology and smart technology have allowed modern people to own various computers, including personal computers and laptops. In addition, the development of smart technology has made it easier to own and utilize various small wireless information devices such as smartphones and tablet PCs. Meanwhile, the development of various communication technologies along with the development of the Internet technologies has made it possible to make communication between people more active.
These computer technologies, smart technologies, and communication technologies have changed our daily lives more conveniently.

Various studies have stated that the correct and appropriate use of smartphone has a positive impact on life in a variety of ways, and representative studies include as follows. A research work has shown that the use and utilization capability of smartphones significantly affect our quality of life in a positive way [1]. In this study, smartphone utilization capability consists of 6 detailed indicators: total cell phone usage time, smartphone usage time out of total cell phone usage time, daily smartphone usage time, smartphone usage days per week, types of smartphones used (operating system), most frequently used smartphone functions. Also, quality of life consists of 6 factors such as economic activity, health and vitality, family relationship, self-respect, emotional state, social life. According to the statistical analysis of the relationship between smartphone utilization capability and quality of life, among the six factors of quality of life, there are statistically significant positive relationships in the remaining five areas except family relationship. In addition, the use of information and communication technologies such as smartphones not only directly positively affects the satisfaction of older people, but indirectly contributes to the satisfaction of older people by expanding their participation in social activities [2]. On the other hand, there is a study that the use of smartphones by older people significantly improves the quality of life, namely living satisfaction, self-respect, and self-effectiveness of older people [3]. As a study of adolescents, there is a study that shows that the use of smartphones by high school students has a significant impact on career maturity and school life satisfaction [4].

Meanwhile, these information and communication technologies and smart technologies have given us convenience while also causing various problems. Typical of these side effects are Internet addiction, privacy violations, pornography distribution, cyberbullying, and Internet gambling. 


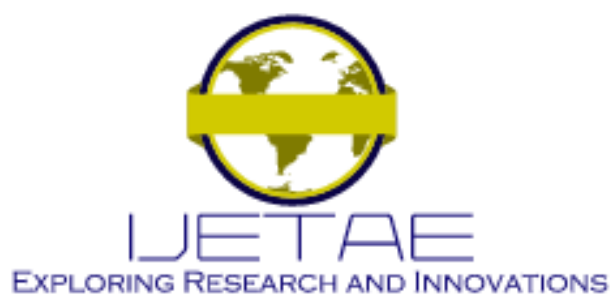

International Journal of Emerging Technology and Advanced Engineering

Website: www.ijetae.com (E-ISSN 2250-2459, Scopus Indexed, ISO 9001:2008 Certified Journal, Volume 11, Issue 08, August 2021)

These side effects cause personal, family and social problems, such as poor health and social maladjustment. Therefore, if these side effects are not properly prevented and cured, it can be a heavy burden on the nation as well. As a study of adolescents, there is a study that shows that the use of smartphones by high school students has a significant impact on career maturity and school life satisfaction [5].

Among those side effects, smartphone addiction or smartphone overdependence is causing serious problems. Especially, smartphone addiction can have a huge impact on our society and nation regardless of age and social class. That is, it can affect all ages, from infants to the elderly, and it can also affect people with various occupations [5$11]$.

The purpose of this study is to analyse the causes of overdependence on smartphones in Korean teenagers and also to suggest solutions. Along with the development of smart technology, the spread and use of smartphones are increasing day by day, and the risk of smartphone addiction is increasing gradually. In particular, recent studies have reported the largest increase in smartphone addiction among teenagers compared to other age groups [12]. In this study, in order to analyse smartphone addiction among Korean teenagers most objectively and reliably, the research was conducted based on the annual smartphone overdependence report published by National Information Society Agency(http://www.nia.or.kr). Since 2004, the agency has released a report on Internet addiction through a nationwide survey, and since 2017, it has released a report on smartphone overdependence instead of Internet addiction.

The rest of this paper is organized as follows. In Section 2 , related works are introduced. First, we present the introduction of smartphone addiction and also discuss related previous research works. In Section 3, we statistically analyse the order of influence among 3 factors of smartphone overdependence in Korean teenagers. In Section 4, we discuss various causes of overdependence on smartphones in Korean teenagers and suggest solutions. Finally, in Section 5, we present conclusions of our works and discuss further research works.

\section{RELATED WORKS}

\section{A. Introduction of Smartphone Addiction}

In the literature, definitions and characteristics of smartphone addiction are as follows.
According to [13], smartphone addiction is defined as "the inability to control excessive use by using smartphones too often and for a long time, and is severely disrupted in daily life, study, etc." [13].

In the meanwhile, in [14] smartphone addiction is defined as "a condition in which excessive use of smartphones leads to withdrawal and resistance to smartphone use, resulting in daily life disorders". Also, in [14], symptoms of smartphone addiction are as follows.

\section{(1) Resistance}

It is a phenomenon that time spent on smartphones is gradually increasing. In other words, smartphone addicts spend longer time using smartphones than in the past and find more stimulating contents. Also, they habitually use smartphones for a long time even though they have no particular purpose.

\section{(2) Withdrawal}

Without a smartphone, they feel anxious and nervous. In other words, if they can't use a smartphone, they can't stand it because they're restless and nervous. Also, it is difficult to concentrate on work (or study) without a smartphone.

\section{(3) Daily life disability}

Excessive smartphone use is causing problems at home, at school, at work, etc. Excessive use of smartphones can reduce academic performance and work efficiency. In addition, they often criticize their family, friends, and people around them for using smartphones often or for a long time, which causes their relationship to be damaged.

\section{(4) Virtual World Orientation}

Rather than meeting in person in real life, it is comfortable to use smartphones to make relationships. They think they will lose the whole world if they don't use a smartphone. Also, a smartphone use is more fun than being with family or friends.

A new term 'smartphone overdependence' is used. Smartphone overdependence consists of 3 states, that is, self-control failure, salience, and serious consequences, respectively [12]. First, the self-control failure means that the user's ability to autonomously control the use of smartphones is poor. Second, salience means that the lifestyle pattern of using a smartphone in an individual's life becomes more prominent and the most important activity than other activities. 


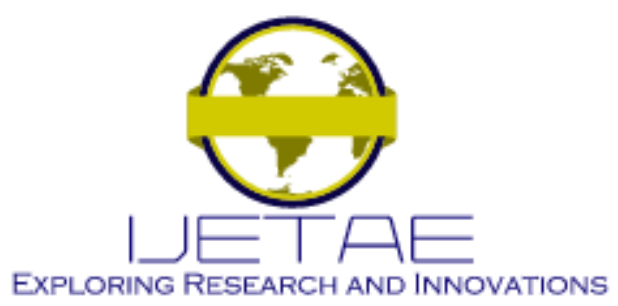

International Journal of Emerging Technology and Advanced Engineering

Website: www.ijetae.com (E-ISSN 2250-2459, Scopus Indexed, ISO 9001:2008 Certified Journal, Volume 11, Issue 08, August 2021)

Third, the serious consequences means that the smartphone continues to be used despite experiencing negative physical, psychological, and social consequences due to the use of the smartphone. Smartphone overdependence is a state in which the 'salience' of the smartphone increases due to excessive use of the smartphone, and the 'self-control failure' increases, resulting in 'serious consequences'. In other words, smartphone overdependence is a condition in which salience is increased, self-control is lost, and serious consequence is faced.

Smartphone overdependence is measured using the following standards. In the paper, in order to reduce confusion in terms, the meaning of smartphone overdependence and smartphone addiction is considered the same. For groups of teenagers, adults, and senior citizens, the following standards are used as in Table 1 [12].

Table 1

Smartphone Overdependence Test Standards for Teenagers, Adults, and Senior Citizens

\begin{tabular}{|c|c|}
\hline Factor & Standards \\
\hline $\begin{array}{l}\text { Self-control } \\
\text { Failure }\end{array}$ & $\begin{array}{l}\text { (1) Whenever I try to reduce my } \\
\text { smartphone usage time, I fail } \\
\text { (2) It is hard for me to control smartphone } \\
\text { usage time } \\
\text { (3) It is hard for me to keep the } \\
\text { appropriate smartphone usage time }\end{array}$ \\
\hline Salience & $\begin{array}{l}\text { (4) It's difficult for me to focus on other } \\
\text { things when I'm next to my smartphone } \\
\text { (5) I can't stop thinking about my } \\
\text { smartphone } \\
\text { (6) I feel a strong urge to use smartphone }\end{array}$ \\
\hline $\begin{array}{c}\text { Serious } \\
\text { Consequence }\end{array}$ & $\begin{array}{l}\text { (7) I have had health problems due to } \\
\text { smartphone use. } \\
\text { (8) I have had a serious fight with my } \\
\text { family due to a smartphone use } \\
\text { (9) have experienced severe conflicts in } \\
\text { friends, colleagues, and social } \\
\text { relationships due to a smartphone use } \\
\text { (10) Due to my smartphone, I have } \\
\text { difficulty in performing my work (such } \\
\text { as studying or working) }\end{array}$ \\
\hline
\end{tabular}

\section{B. Previous Works}

There have been some research works for causes and solutions on teenagers' smartphone addiction as follows.
In [15], it is verified that narcissistic tendencies and divisive personality traits play a mediating role in the smartphone addiction process affecting relational aggression in middle school girls. To this end, 378 middle school girls participated in the study in Gyeonggi and Chungcheong regions were analyzed. The following methods were used for data analysis. First, the sociodemographic characteristics of the participants were analyzed for basic data analysis and the average and standard deviation of the variables were obtained. Second, Pearson correlation coefficients were obtained to correlate between participants. Third, after conducting a verifiable factor analysis to verify the measurement model, the structural equation model was designed and validated. The main findings are as follows. First, smartphone addiction showed a significant static correlation with narcissistic tendencies, divisive personality traits, relational aggression, and narcissistic tendencies. Also, divisive personality traits showed a static correlation with relational aggression. Second, narcissistic tendencies played a full role in the smartphone addiction process affecting relational aggression. Third, split personality traits played a partial relationship between smartphone addiction and relational aggression.

The study in [16] was conducted with the aim of analyzing the structural relationship between adolescents' smartphone addiction and resilience, aggression, and school adaptation. The research data were collected from 177 male high school students and 191 female high school students. Analysis has shown that smartphone addiction has a big impact on aggression and school adaptation through the medium of resilience. Consequently, resilience has been found to fully mediate the relationship between aggression and school adaptation.

In [17], the purpose of the study is to investigate the influences of smartphone addiction and online delinquency to offline delinquency, and the influences of smartphone addiction to online delinquency in adolescents. Data for this study were collected by 802 adolescents from the first grade of middle school to the second grade in high school. In this study, frequency analysis was performed to examine the general characteristics of the subjects, and simple correlation analysis was performed to examine correlations between variables. In addition, the principal component analysis of the factor analysis was conducted to verify the validity of the measurement variable, which is a subtype of each major latent variable. 


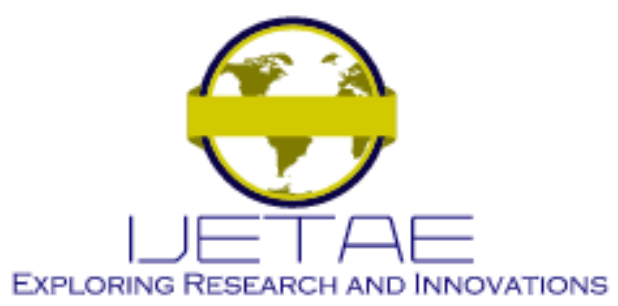

International Journal of Emerging Technology and Advanced Engineering

Website: www.ijetae.com (E-ISSN 2250-2459, Scopus Indexed, ISO 9001:2008 Certified Journal, Volume 11, Issue 08, August 2021)

Based on the analysis result using structural equation modeling, it is concluded that smartphone addiction was not found to affect directly offline delinquency. However, smartphone addiction has a big effect on online delinquency and, on the other hand, online delinquency also has significant effect on offline delinquency. For the relation of smartphone addiction and offline delinquency, online delinquency was found as the complete mediating effect.

In [18], they analyze the effects of teenagers' motivation to use smartphones on smartphone addiction and the control effect of social support. The subjects of this study were 659 teenagers attending high school and analyzed by hierarchical regression analysis. The main findings are as follows. First, motivations for pursuing information among smartphone uses have been shown to negatively affect smartphone addiction, and motivations for pursuing entertainment have a static impact on smartphone addiction. Second, social support has shown a negative effect on smartphone addiction. Third, social support has been shown to have a static control effect in the pursuit of relationships. On the other hand, social support has been shown to have a negative control effect on time-spending motivation.

The study in [19] analyzed digital literacy and social and environmental factors of children and adolescents, which are personal factors as predicting the level of smartphone addiction in children and adolescents. Specifically, they investigate the mother's level of smartphone addiction, parental intervention conducted by the mother, and the effects of her digital literacy. To this end, a total of 92 families, including children and teenagers who use smartphones and their mothers, were surveyed among fourth-grade elementary school students and second-grade middle school students aged 10-14 years. First of all, the higher the mother's smartphone addiction status, the higher her child's smartphone addiction status, while the higher the mother's functional digital literacy status, the lower her child's smartphone addiction status. In addition, mother mediation was not related to her child's level of smartphone addiction, but the degree of media-related critical communication among peer groups, one of the control variables, showed a negative relationship with the smartphone addiction status. It was also confirmed that the role of peers may be more important than the role of mothers as a factor affecting the media usage behavior of children and adolescents.
The limitations of this study are as follows. First of all, the number of samples used in the study is 92 families, and it is difficult to generalize the results of the study because it is recruited in a specific region. Also, even if the mother's influence on her child can be greater than that of her father, it is necessary to check what the father's role is in media use. Other variables need to be considered regarding the impact of a mother's level of smartphone addiction on her child's level of smartphone addiction.

In [20], the correlation between children of dual-income family and internet addiction is analyzed. It is shown that, although the internet addiction rate of dual-income families was higher than single-income families, there was no significant correlation. As a similar work, in [21], correlation between internet addiction and teenagers' smartphone addiction was analyzed. Based on the statistical analysis, it is shown that there is a significant correlation between internet addiction and smartphone addiction.

In [11], this study examined the effects of smartphone dependence on cyber delinquency in adolescents, and also examined the regulatory effects on smartphone dependence of individual psychological and relational factors. Individual psychological factors included depression and self-respect, relationships between friends and teachers. The analysis included 1,303 male and 1,101 female teenagers. In this study, frequency analysis was conducted to examine the socio-demographic characteristics of the study subjects, and Cronbach's alpha was calculated to verify the reliability of measurement tools. In addition, Pearson correlation was conducted to identify the relationship between each variant. The results of the analysis are as follows: First, in the case of personal psychological factors, depression and self-respect were found to control the impact of smartphone dependence on cyber delinquency only in male adolescents. Second, in the case of relational factors, both male and female teenagers were found to control the impact of smartphone dependence on cyber delinquency, while teacher relationships were not significant in both male and female adolescents. This study found that male teenagers are more vulnerable to cyber delinquency if individual psychological factors such as depression and self-respect are not stable, and friendship is an important factor for both male and female teenagers. These results suggested that improving friendships for the reduction of cyber delinquency among teenagers would be helpful. The limitations of this study are as follows. 


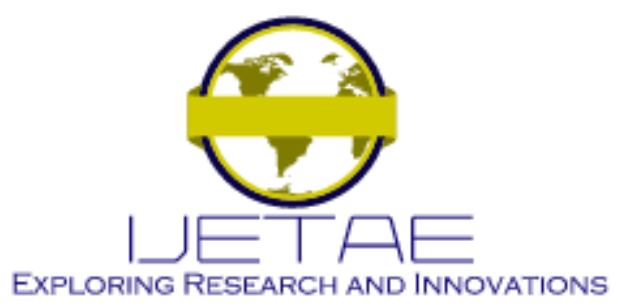

International Journal of Emerging Technology and Advanced Engineering

Website: www.ijetae.com (E-ISSN 2250-2459, Scopus Indexed, ISO 9001:2008 Certified Journal, Volume 11, Issue 08, August 2021)

First, this study is meaningful in that it found genderspecific differences by analyzing them according to gender, but there is a limitation only for second graders in middle school. In addition, the smartphone dependency used in this study was not investigated according to the type of service used in smartphones. Considering the research showing that life satisfaction and self-respect vary depending on the type of service used, analysis according to the type of service used by smartphones is necessary.

So far, we have introduced various studies on smartphone addiction or overdependence among Korean teenagers. Most of the studies were conducted on specific regions and specific people, which could not analyze the causes of smartphone overdependence on all Korean teenagers, nor could solutions be generalized and presented. Therefore, research based on data representing all Korean teenagers is needed.

The following Table 2 show the summarization of the previous related works.

Table 2

Summarization of the Previous Works

\begin{tabular}{|c|c|}
\hline Reference & Summary \\
\hline 11 & $\begin{array}{l}\text { This study examined the effects of smartphone } \\
\text { dependence on cyber delinquency in adolescents, } \\
\text { and also examined the regulatory effects on } \\
\text { smartphone dependence of individual } \\
\text { psychological and relational factors. }\end{array}$ \\
\hline 15 & $\begin{array}{l}\text { it is verified that narcissistic tendencies and } \\
\text { divisive personality traits play a mediating role in } \\
\text { the process of smartphone addiction affecting } \\
\text { relational aggression in middle school girls }\end{array}$ \\
\hline 16 & $\begin{array}{l}\text { The structural relationship between adolescents' } \\
\text { smartphone addiction and resilience, aggression, } \\
\text { and school adaptation is analyzed. }\end{array}$ \\
\hline 17 & $\begin{array}{l}\text { The influences of smartphone addiction and online } \\
\text { delinquency to offline delinquency, and the } \\
\text { influences of smartphone addiction to online } \\
\text { delinquency in adolescents are investigated. }\end{array}$ \\
\hline 18 & $\begin{array}{l}\text { The effects of teenagers' motivation to use } \\
\text { smartphones on smartphone addiction and the } \\
\text { control effect of social support are analyzed. }\end{array}$ \\
\hline 19 & $\begin{array}{l}\text { Digital literacy and social and environmental } \\
\text { factors of children and adolescents are analyzed. }\end{array}$ \\
\hline 20 & $\begin{array}{l}\text { The correlation between dual-income family home } \\
\text { children and internet addiction is analyzed }\end{array}$ \\
\hline Implication & $\begin{array}{l}\text { Based on statistics at the national level, objective } \\
\text { research is needed to determine the cause of } \\
\text { teenagers' overdependence on smartphones. }\end{array}$ \\
\hline
\end{tabular}

\section{Statistical ANALYSIS OF SMARTPHONE OVERDEPENDENCE IN TEENAGERS}

In this section, we present a statistical analysis on smartphone overdependence of Korean teenagers as follows.

\section{A. Introduction of Smartphone Addiction}

For the smartphone overdependence status analysis of this paper, we adopted national statistical data from National Information Society Agency(http://www.nia.or.kr) $[12,22-24]$. The agency has announced Internet addiction status report since 2004. The agency has also reported smartphone overdependence status report since 2017.

For the fair analysis, the agency collected various data evenly based on gender, occupation, age groups, and regions, etc. Also, for the accurate analysis, the agency has adopted a household visit interview method. According to the latest report [12], sample size includes 10,000 households (30,927 interviewee).

In this work, we analyse using the Statistical Package for the Social Science (SPSS) WIN 25.0 program. One-way ANOVA was conducted to identify factors that determine smartphone overdependence for teenagers.

\section{B. Survey Data}

Factors for teenagers' smartphone overdependence based on National Information Society Agency [12,22-24] are summarized as follow.

First, the results of the survey on 3 factors for teenagers' smartphone overdependence over the four years from 2017 to 2020 are shown in Table 3.

Table 3

Factors for Teenagers' Smartphones Overdependence by Year (Unit: 4-point Scale)

\begin{tabular}{|c|l|l|l|}
\hline Year & $\begin{array}{c}\text { Self-control } \\
\text { Failure }\end{array}$ & Salience & $\begin{array}{c}\text { Serious } \\
\text { Consequences }\end{array}$ \\
\hline 2017 & 2.86 & 2.70 & 2.46 \\
\hline 2018 & 3.01 & 2.93 & 2.54 \\
\hline 2019 & 3.06 & 2.93 & 2.48 \\
\hline 2020 & 2.98 & 2.79 & 2.35 \\
\hline
\end{tabular}

To investigate the causes of teenagers' overdependence on smartphones, we first looked at the overdependence solvers of smartphones. Table 4 shows the results of the survey. 


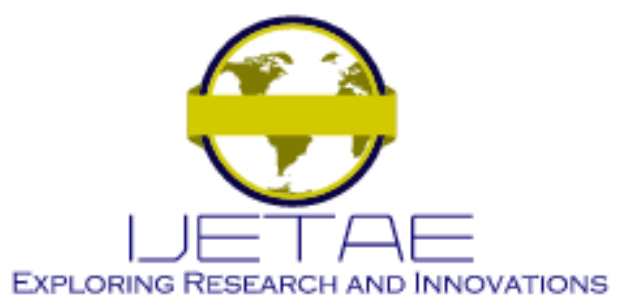

International Journal of Emerging Technology and Advanced Engineering

Website: www.ijetae.com (E-ISSN 2250-2459, Scopus Indexed, ISO 9001:2008 Certified Journal, Volume 11, Issue 08, August 2021)

As shown in Table 4, the majority of over-dependent teenagers responded that individuals were the main solver of overdependence.

Table 4

Overdependence Solver (Unit: \%) $[8,18,19]$

\begin{tabular}{|c|c|c|c|}
\hline & Individual & Company & Government \\
\hline 2020 & 60.4 & 22.4 & 17.2 \\
\hline 2019 & 68.2 & 17.9 & 13.9 \\
\hline 2018 & 70.5 & 17.6 & 12.0 \\
\hline
\end{tabular}

Meanwhile, Table 5 shows the results of a survey of over-dependent teenagers on obstruction factors in resolving individual overdependence. Two main obstacles are habitual smartphone use and the fun to be gotten from using a smartphone.

Table 5

Obstruction Factors in Resolving Individual Overdependence (Unit: \%) [12,22,23]

\begin{tabular}{|l|l|l|l|l|}
\hline & (2) & (2) & (3) & (4) \\
\hline 2020 & 46.0 & 29.4 & 11.5 & 13.2 \\
\hline 2019 & 33.2 & 32.3 & 14.8 & 19.6 \\
\hline 2018 & 20.5 & 54.7 & 21.3 & 3.5 \\
\hline
\end{tabular}

Where

(1): Habitual smartphone use

(2): The fun to be gotten from using a smartphone.

(3): Inevitable use of learning or work

(4): Communication with friends and acquaintances

Table 6 also shows the number one solution for overdependent teenagers to overdependence on smartphones. They responded that the major solution is through strengthening self-regulating ability.

Table 6

Number One Solution to Overdependence (Unit: \%) [12,22,23]

\begin{tabular}{|l|l|l|l|l|l|l|}
\hline & (1) & (2) & (3) & (4) & (5) & (6) \\
\hline 2020 & 55.1 & 16.4 & 13.4 & 7.0 & 5.1 & 3.0 \\
\hline 2019 & 45.1 & 21.1 & 12.7 & 8.7 & 8.5 & 3.9 \\
\hline 2018 & 46.3 & 18.3 & 15.8 & 10.0 & 5.8 & 3.9 \\
\hline
\end{tabular}

Where

(1): Strengthen self-regulating ability

(2): Use control app such as time management

(3): Expanding time spent with family members, such as child supporting time;

(4): Legal/Institutional Improvements

(5): Implementation of expansion of preventive education

6): Strengthen awareness campaigns

Meanwhile, Table 7 shows the results of responses to the number one smartphone over-dependence solving action among over-dependent teenagers. It can be seen that the first priority is use of alternative leisure activities.

Table 7

Number One Individual's Solving Action to Overdependence (Unit: \%) $[12,22,23]$

\begin{tabular}{|l|l|l|l|l|}
\hline & (1) & (2) & (3) & (4) \\
\hline 2020 & 37.3 & 24.5 & 23.9 & 14.2 \\
\hline 2019 & 37.6 & 21.6 & 24.8 & 16.0 \\
\hline 2018 & 37.3 & 22.5 & 27.7 & 12.5 \\
\hline
\end{tabular}

Where

(1): Use of alternative leisure activities (culture, sports, travel).

(2): Willingness to control individual use

(3): Advice and help from family and friends

(4): Technical support such as usage control apps

Meanwhile, Tables 8 and 9 show the results of the survey on the main leisure activities of over-dependent teenagers.

Table 8

The Main Leisure Activity (Unit: \%) [12]

\begin{tabular}{|l|l|l|l|l|l|l|l|l|}
\hline & (1) & (2) & (3) & (4) & (5) & (6) & (7) & (8) \\
\hline 2020 & 11.6 & 58.3 & 9.6 & 6.5 & 6.2 & 5.8 & 1.9 & 0.1 \\
\hline
\end{tabular}

Where

(1): Relaxation activities (TV viewing, mountain climbing, walking, etc.)

(2): Using a Smartphone

(3): Hobby \& Entertainment (Shopping/Dining out)

(4): Social and other activities (meeting friends, religious activities, etc.) 


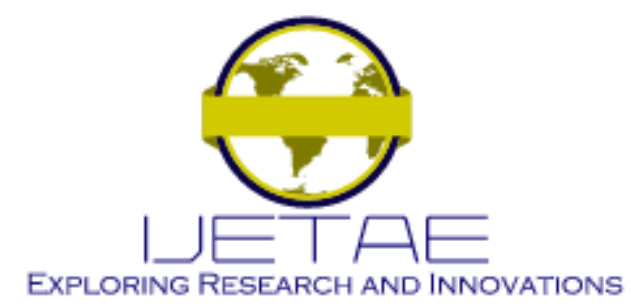

International Journal of Emerging Technology and Advanced Engineering

Website: www.ijetae.com (E-ISSN 2250-2459, Scopus Indexed, ISO 9001:2008 Certified Journal, Volume 11, Issue 08, August 2021)

(5): Watching and participating in sports

(6): Participation and viewing of culture and arts

(7): Tourism activities (watching natural sights, camping, etc.)

8): Other Activities

Table 9

The Main Leisure Activity (Unit: \%) [22,23]

\begin{tabular}{|l|l|l|l|l|l|l|l|l|}
\hline & (1) & (2) & (3) & (4) & (5) & (6) & (7) & (8) \\
\hline 2019 & 24.2 & 45.0 & 8.0 & 6.0 & 6.9 & 6.8 & 2.5 & 0.6 \\
\hline 2018 & 27.1 & 44.9 & 9.2 & 7.6 & 5.1 & 4.8 & 1.4 & 0.0 \\
\hline
\end{tabular}

Where

(1): Watching TV

(2): Game/Internet Search

(3): Rest

(4): Hobbies/Self-development Activities

(5): Participation and viewing of culture and arts

6): Watching and participating in sports

(7): Social activities

(8): Other Activities

Tables 10 and 11 show the results of the survey on the desired leisure activities of over-dependent teenagers.

Table 10

First priority for Leisure Activities Desired (Unit: \%) [12]

\begin{tabular}{|l|l|l|l|l|l|l|l|l|}
\hline & (1) & (2) & (3) & (4) & (5) & (6) & (7) & (8) \\
\hline 2020 & 8.3 & 40.6 & 12.3 & 9.7 & 8.2 & 14.8 & 5.9 & 0.2 \\
\hline
\end{tabular}

Where items are the same as Table 6

Table 11

First priority for Leisure Activities Desired (Unit: \%) [18,19]

\begin{tabular}{|c|c|c|c|c|c|c|c|c|}
\hline & (1) & (2) & (3) & (4) & (5) & (6) & (7) & (8) \\
\hline 2019 & 20.7 & 35.7 & 9.3 & 7.3 & 15.5 & 6.7 & 4.1 & 0.6 \\
\hline 2018 & 19.2 & 33.8 & 10.3 & 11.3 & 14.7 & 8.3 & 2.4 & 0.0 \\
\hline
\end{tabular}

Where items are the same as Table 7

\section{Statistical Analysis Results}

First, the analysis of the importance of the three factors of teenagers' smartphone overdependence is shown in Table 12.
Table 12

Analysis Results of the 3 Factors

\begin{tabular}{|c|l|l|c|c|}
\hline Factors & Mean & SD & F & p \\
\hline Self-control Failure & 2.98 & 0.09 & & \\
\hline Salience & 2.84 & 0.11 & \multirow{3}{*}{$33.07 * * *$} & 0.000 \\
\hline $\begin{array}{c}\text { Serious } \\
\text { Consequences }\end{array}$ & 2.46 & 0.08 & & \\
\hline $\begin{array}{c}\text { Overall } \\
\text { *** } \mathrm{p}<0.001\end{array}$ & 2.76 & 0.24 & & \\
\hline
\end{tabular}

Looking at the smartphone overdependence factors among teenagers, the average was the highest at 2.98 in selfcontrol failure, followed by 2.84 in salience, 2.46 in serious consequences, and showed statistically significant differences $(\mathrm{F}=33.07, \mathrm{p}<0.001)$. Thus, teenagers have the highest dependence on smartphones due to self-control failure, and important factor in teenagers' smartphone overdependence is the order of self-control failure, salience, and serious consequences, respectively.

We first make the following six hypotheses about the causes and solutions of overdependence on teenagers' smartphones. The following six hypotheses were developed to objectively determine the cause of Korean teenagers' smartphone overdependence from the National Information Society Agency's national statistics.

\section{Hypothesis 1:}

The overdependence solver is the 'individual'.

\section{Hypothesis 2:}

Obstruction factors in resolving individual overdependence are 'habitual smartphone use' and 'the fun to be gotten from using a smartphone'.

\section{Hypothesis 3:}

Number one solution to overdependence is 'strengthening self-regulating ability'.

\section{Hypothesis 4:}

Number one individual's solving action to overdependence is 'use of alternative leisure activity'. 


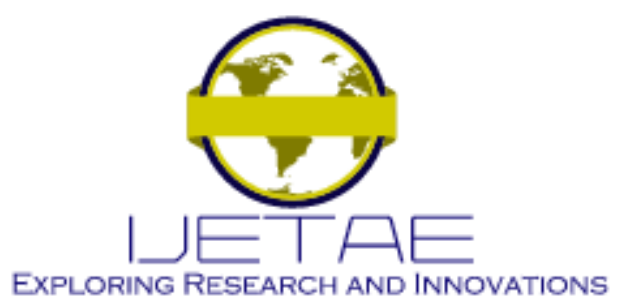

International Journal of Emerging Technology and Advanced Engineering

Website: www.ijetae.com (E-ISSN 2250-2459, Scopus Indexed, ISO 9001:2008 Certified Journal, Volume 11, Issue 08, August 2021)

Hypothesis 5:

The main leisure activity is 'game/Internet search/smartphone use'.

\section{Hypothesis 6:}

First priority for leisure activities desired is ' game/ Internet search/smartphone use'.

To investigate whether Hypothesis 1 is supported, statistical analysis was conducted on Table 4 and the results are as shown in Table 12. As shown in Table 13, individual averaged 66.37, followed by company 19.30 and government 14.37 , with statistically significant differences $(\mathrm{F}=117.22, \mathrm{p}<0.001)$. Therefore, hypothesis 1 is supported.

Table 13

Statistical Analysis of Overdependence Solver

\begin{tabular}{|l|l|l|l|l|}
\hline & Mean & SD & F & P \\
\cline { 1 - 3 } Individual & 66.37 & 5.29 & & \\
\cline { 1 - 3 } Company & 19.30 & 2.69 & \multirow{2}{*}{$117.22 * * *$} & 0.000 \\
\cline { 1 - 3 } Government & 14.37 & 2.63 & & \\
\hline
\end{tabular}

$* * * \mathrm{p}<0.001$

On the other hand, to investigate whether Hypothesis 2 is supported, statistical analysis was conducted on Table 5 and the results are as shown in Table 14. As shown in Table 14, the average of the fun to be gotten from using a smartphone was 38.80, followed by habitual smartphone use 33.23, inevitable use of learning or work 15.87 and communication with friends and acquaintances $12.10(\mathrm{~F}=3.43$ and $\mathrm{p}>0.05)$. Therefore, hypothesis 2 has been rejected.

Table 14

Statistical Analysis of Obstruction Factors in Resolving Individual Overdependence

\begin{tabular}{|l|l|c|c|c|}
\hline & Mean & SD & F & p \\
\hline $\begin{array}{l}\text { Habitual smartphone } \\
\text { use }\end{array}$ & 33.23 & 12.75 & & \\
\hline $\begin{array}{l}\text { The fun to be gotten } \\
\text { from using a } \\
\text { smartphone. }\end{array}$ & 38.80 & 13.85 & \multirow{2}{*}{3.43} & 0.093 \\
$\begin{array}{l}\text { Inevitable use of } \\
\text { learning or work }\end{array}$ & 15.87 & 4.99 & 8.11 & \\
$\begin{array}{l}\text { Communication with } \\
\text { friends and } \\
\text { acquaintances }\end{array}$ & 12.10 & & \\
\hline
\end{tabular}

In order to investigate whether Hypothesis 3 is supported, based on Table 6, the statistical analysis is conducted and results are shown in Table 15. As shown in Table 15, the average of 'strengthen self-regulation ability' was the highest at 48.83 , followed by 'use control app such as time management' 18.60 , followed by 'expanding time spent with family members' 13.97, 'legal/institutional improvements' 8.57 , and 'implementation of expansion of prevention education' 6.47, and 'strengthen awareness campaigns' at 3.60 , and statistically significant difference $(\mathrm{F}=94.93, \mathrm{p}<0.001)$. Therefore, hypothesis 3 was supported.

Table 15

Statistical Analysis of Number One Solution to Overdependence

\begin{tabular}{|c|c|c|c|c|}
\hline & Mean & SD & $\mathbf{F}$ & $\mathbf{p}$ \\
\hline $\begin{array}{l}\text { Strengthen } \\
\text { regulating ability }\end{array}$ & 48.83 & 5.46 & \multirow{6}{*}{$94.93 * * *$} & \multirow{6}{*}{0.000} \\
\hline $\begin{array}{l}\text { Use control app such as } \\
\text { time management }\end{array}$ & 18.60 & 2.36 & & \\
\hline $\begin{array}{l}\text { Expanding time spent } \\
\text { with family members }\end{array}$ & 13.97 & 1.63 & & \\
\hline $\begin{array}{l}\text { Legal/Institutional } \\
\text { Improvements }\end{array}$ & 8.57 & 1.50 & & \\
\hline $\begin{array}{l}\text { Implementation of } \\
\text { expansion of preventive } \\
\text { education }\end{array}$ & 6.47 & 1.80 & & \\
\hline $\begin{array}{l}\text { Strengthen awareness } \\
\text { campaigns }\end{array}$ & 3.60 & 0.52 & & \\
\hline
\end{tabular}

$* * * \mathrm{p}<0.001$

In order to identify whether hypothesis 4 is supported, statistical analysis was conducted based on Table 7 and the results are as shown in Table 16. As shown in Table 16, the average of 'use of alternative leisure activities' was 37.40, followed by 'advice and help from family and friends' 25.47 , followed by 'willingness to control individual use' 22.87, 14.23 for 'technical support such as usage control apps', and statistically significant differences $(\mathrm{F}=89.12$, $\mathrm{p}<0.001)$. Therefore, hypothesis 4 was supported. 


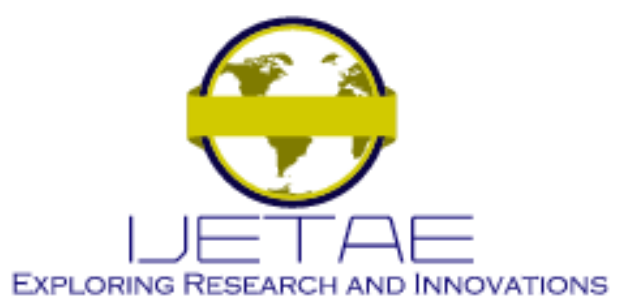

International Journal of Emerging Technology and Advanced Engineering

Website: www.ijetae.com (E-ISSN 2250-2459, Scopus Indexed, ISO 9001:2008 Certified Journal, Volume 11, Issue 08, August 2021)

Table 16

Statistical Analysis of Number One Individual Solving Action to Overdependence

\begin{tabular}{|c|c|c|c|c|}
\hline & Mean & SD & $\mathbf{F}$ & $\mathbf{p}$ \\
\hline $\begin{array}{l}\text { Use of alternative } \\
\text { leisure activities }\end{array}$ & 37.40 & 0.17 & \multirow{4}{*}{$89.12 * * *$} & \multirow{4}{*}{0.000} \\
\hline $\begin{array}{l}\text { Willingness to control } \\
\text { individual use }\end{array}$ & 22.87 & 1.48 & & \\
\hline $\begin{array}{l}\text { Advice and help from } \\
\text { family and friends }\end{array}$ & 25.47 & 1.99 & & \\
\hline $\begin{array}{l}\text { Technical support such } \\
\text { as usage control apps }\end{array}$ & 14.23 & 1.75 & & \\
\hline
\end{tabular}

In order to identify whether hypothesis 5 is supported or not, statistical analysis was conducted based on Table 8 and 9 , and the results are as shown in Table 17. Note that the items in the two tables 8 and 9 are joined together by similar ones in Table 17. As shown in Table 17, among leisure activities, smartphone use/games/internet search had the highest average at 51.65 , followed by relaxation activities 21.90, hobby \& entertainment activities 7.80, sports watching and participation 6.50, culture and arts participation and viewing 6.35 , Social and other activities 5.45 , other activities were the lowest at 0.35 , and statistically significant differences were also shown $(\mathrm{F}=11.63, \mathrm{p}<0.01)$. Therefore, it can be seen that Hypothesis 5 was supported.

Table 17

Statistical Analysis of the Main Leisure Activity

\begin{tabular}{|c|c|c|c|c|}
\hline & Mean & SD & $\mathbf{F}$ & $\mathbf{p}$ \\
\hline $\begin{array}{l}\text { Relaxation activities (TV } \\
\text { watching, walking, etc.) }\end{array}$ & 21.90 & 14.57 & \multirow{7}{*}{$\begin{array}{l}11.6 \\
3 * *\end{array}$} & \multirow{7}{*}{0.004} \\
\hline $\begin{array}{l}\text { Smartphone Use/ } \\
\text { Game/Internet Search }\end{array}$ & 51.65 & 9.40 & & \\
\hline $\begin{array}{l}\text { Hobby \& Entertainment } \\
\text { (Shopping/Dining out) }\end{array}$ & 7.80 & 2.55 & & \\
\hline Social and other activities & 5.45 & 4.17 & & \\
\hline $\begin{array}{l}\text { Watching and } \\
\text { participating in sports }\end{array}$ & 6.50 & 0.42 & & \\
\hline $\begin{array}{l}\text { Participation and viewing } \\
\text { of culture and arts }\end{array}$ & 6.35 & 0.78 & & \\
\hline Other Activities & 0.35 & 0.35 & & \\
\hline
\end{tabular}

$* * \mathrm{p}<0.01$
Finally, in order to investigate whether hypothesis 6 is supported or not, statistical analysis was conducted based on Table 10 and 11, and the results are as shown in Table 18. Note that the items in the two tables 10 and 11 are joined together by similar ones in Table 18. As shown in Table 18, among leisure activities desired, smartphone use/games/internet search had the highest average of 38.15, followed by relaxation activities at 19.15, cultural and art participation and viewing at 15.15 , social and other activities 9.85 , hobby \& entertainment activities 9.80, sports watching and participation in the order of 7.45. Other activities had the lowest score of 0.40 , and there was a statistically significant difference $(\mathrm{F}=5.33, \mathrm{p}<0.05)$. Therefore, it can be seen that Hypothesis 6 was supported.

Table 18

Statistical Analysis of First Priority for Leisure Activity Desired

\begin{tabular}{|c|c|c|c|c|}
\hline & Mean & SD & $\mathbf{F}$ & p \\
\hline $\begin{array}{l}\text { Relaxation activities (TV } \\
\text { watching, walking, etc.) }\end{array}$ & 19.15 & 15.34 & \multirow{7}{*}{$5.33 *$} & \multirow{7}{*}{0.031} \\
\hline $\begin{array}{ll}\text { Smartphone } & \text { Use/ } \\
\text { Game/Internet Search } & \end{array}$ & 38.15 & 3.46 & & \\
\hline $\begin{array}{l}\text { Hobby Entertainment } \\
\text { (Shopping/Dining out) }\end{array}$ & 9.80 & 3.54 & & \\
\hline Social and other activities & 9.85 & 8.13 & & \\
\hline $\begin{array}{l}\text { Watching and participating } \\
\text { in sports }\end{array}$ & 7.45 & 1.06 & & \\
\hline $\begin{array}{l}\text { Participation and viewing of } \\
\text { culture and arts }\end{array}$ & 15.15 & 0.49 & & \\
\hline Other Activities & 0.40 & 0.28 & & \\
\hline
\end{tabular}

$* \mathrm{p}<0.05$

\section{DISCUSSION}

Korean smartphone over-dependent teenagers consider themselves to be the problem solvers of overdependence, and hope to reduce the use of smartphones through alternative leisure activities through self-regulation. However, habitual smart use and fun with smartphones act as obstacles. Therefore, providing healthy alternative leisure activities for over-dependent teenagers is a top priority in solving smartphone overdependence. 


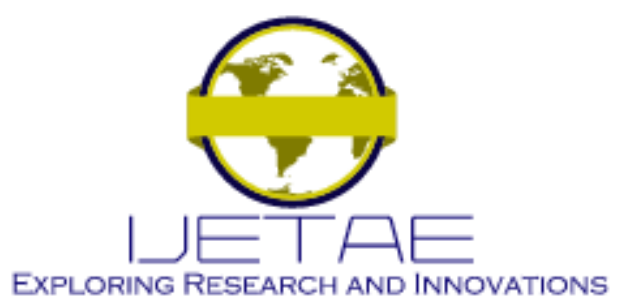

International Journal of Emerging Technology and Advanced Engineering

Website: www.ijetae.com (E-ISSN 2250-2459, Scopus Indexed, ISO 9001:2008 Certified Journal, Volume 11, Issue 08, August 2021)

From significant conclusions based on statistical analysis results, the following measures are needed for teenagers' overdependence on smartphones as follows.

First of all, it is seen that Korean smartphone overdependents try to solve their own problems. However, the big problem is that addiction cannot be solved by the addict's own efforts, along with other addiction problems such as gambling addiction. Therefore, teenagers who are overdependent on smartphones should reveal their problems and get help from schools and homes. The important thing is not to blame the smartphone overdependent teenagers at home or at school, but to encourage them. Meanwhile, families have limitations in providing systematic education or counselling programs. Therefore, schools must first and foremost provide formal smartphone overdependence prevention programs and healing programs. It is also necessary to set up a dedicated teacher or department related to overdependence on smartphones in schools.

Also, the problem is that teenagers who over-dependent on smartphones solve their over-dependence problems through sound leisure activities, but have no other leisure activities other than using the Internet or using smartphones. As smartphones are used during leisure activities, the vicious cycle of using smartphones will inevitably be repeated. Therefore, it is very important to develop and disseminate healthy leisure activities for teenagers who are overdependent on smartphones. Recent studies have identified a correlation in which teenagers participate in physical activities to alleviate academic problems caused by smartphones. Also, it is argued that it is necessary to encourage teenagers to participate in physical activities to alleviate academic problems caused by smartphones [25].

Meanwhile, online education has recently been strengthened due to environmental factors such as covid19 , which is expected to inevitably increase the use of smartphones by teenagers. In other words, since smartphones are becoming a major means of learning for teenagers, there is a limit to reducing the use of smartphones themselves. In other words, using a smartphone to teach how to refrain from using it can be a good way. Recently, educational use of serious games has become more active, so it would be a good idea to develop the smartphone control ability of teenagers through functional games.

\section{CONCLUSIONS AND FURTHER RESEARCH WORKS}

The development of information and communication technology and smart technology is benefiting modern people a lot. In particular, the development of smart technology in pursuit of miniaturization and simplification has led to the development and distribution of various smart devices, among which smartphones have become a necessity for modern people. However, these smartphones are showing us a dual aspect of convenience and side effects. Among the various side effects of smartphones, overdependence is getting worse sharply, especially the percentage of Korean teenagers' overdependence is increasing rapidly compared to other age groups.

In this work, we statistically analyse the priority of influence among the three factors (self-control failure, salience, and serious consequences) of smartphone overdependence. Based on this, our goal of this research work is to ultimately identify the causes of overdependence on smartphones and suggests solutions. Among the three factors of overdependence, self-control failure was the biggest factor, followed by salience, and serious consequences. Over-dependent teenagers think that strengthening self-control ability and alternative leisure activities are the main solutions to reduce their habitual use of smartphones. The most important solution for overdependent teenagers is to provide sound alternative leisure activities other than smartphone use.

In this study, three ways are proposed to solve the problem of over-dependence among teenagers who are over-dependent on smartphones. First, we insist the establishment of a dedicated department in schools and the designation of dedicated teachers. Second, it is necessary to develop and disseminate leisure activities including physical activities. Third, it is also necessary to help teenagers control their smartphone usage by developing various serious games.

Future research works in this paper are as follows. First, it is to provide psychological prevention and counselling education by investigating and analysing the psychological conditions of over-dependent teenagers. For this purpose, more literature works and statistical analysis works are required. Second, it is to provide effective healing methods for smartphone over-dependent teenagers. Therefore, it is necessary to develop various healing methods by education and counselling in the near future. 


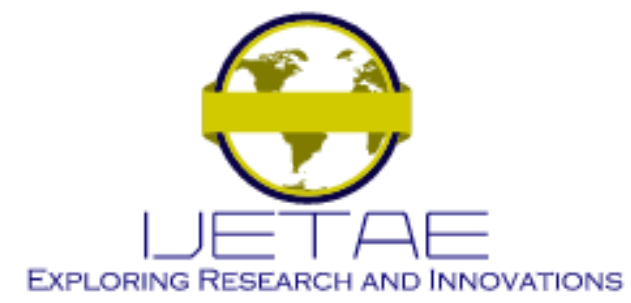

International Journal of Emerging Technology and Advanced Engineering

Website: www.ijetae.com (E-ISSN 2250-2459, Scopus Indexed, ISO 9001:2008 Certified Journal, Volume 11, Issue 08, August 2021)

\section{REFERENCES}

[1] Han, S.Y., Ma, E.J., Choi, S.K., Hong, D.S. "Analysis on the Impact of Using Smart-phone to Subjective Quality of Life", Information Society \& Media. 2011, 20, 49-84.

[2] Kim, M.Y., Jun, H.J. "The Effects of Smartphone Use on Life Satisfaction in Older Adults: The Mediating Role of Participation in Social Activities", Korean Journal of Gerontological Social Welfare. 2017, 72(3), 343-370, https://doi.org/10.21194/kjgsw.72.3.201709.343

[3] Han, J.R., Kim, S.W., Suh, J.B. "The Effect of Mobile Phone Education for the Elderly to Eliminate the Digital Divide between Generations", Korean Journal of Educational Gerontology, 2019, 5(1), 43-61, https://doi.org/10.31748/KSEG.2019.5.1.43

[4] Kim, D.S., Yoon, M.H., Jung, E.H. "A Study on the Influence of Self-determination Based on Basic Needs Theory for the Use of Smartphone on Career Maturity and School Life Satisfaction: Focused on Vocational High School Students", Social Science Review. 2020, 51(1), 215-230, https://doi.org/10.31502/SSRI.51.1.9

[5] Kim, K.E., Cho, S.Y. "Analysis of Motivation for Change and Selfregulation Difficulties of Korean College Students Addicted to Smart-phone", The Journal of Learner-Centered Curriculum and Instruction. $\quad 2019, \quad 19(23), \quad$ 1057-1082, http://dx.doi.org/10.22251/jlcci.2019.19.23.1057

[6] Cho, H.S. "A Study on the Solution for the Internet, Smartphone, and Internet Game Addiction of Teenagers", Korean Journal of Youth Studies. 2019, 26(10), 291-310, http://dx.doi.org/10.21509/KJYS.2019.10.26.10.291

[7] Lee, K.N. and Kim, H.H. "The Relationship of Parent-Child Communication, Loneliness and Interpersonal Problems on Adolescents' Smartphone Addiction", Youth Facilities and Environment. 2019, 17(3), 27-36.

[8] Lee, S.J. "An Analysis on the Mental Health of Adolescent Addicted to Smartphone", Journal of Youth Welfare. 2018, 20(3), 47-67, http://dx.doi.org/10.19034/KAYW.2018.20.3.03

[9] Lee, S.J. "The Moderating Effect of Self-esteem, Family Support, Parents-Adolescent Communication on Mental Health of Adolescents' Smartphone Addiction”, Social Science Research Review. 2017, 33(4), 75-95, http://dx.doi.org/10.18859/ssrr.2017.11.33.4.75

[10] Kang, Y.S., Bhang, S.Y., Yoon, J.Y., Han, S.R., Choi, J.W. "Relationship Between Adolescents' Internet-Gaming/Smartphone Addiction and Parents' Involvement", Journal of Korean Academy of Addiction Psychiatry. 2021, 25(1), 28-33, http://doi.org/10.37122/kaap.2021.25.1.28

[11] Choi, H.S. "The Effect of Smartphone Dependency on Cyber Delinquency of Adolescents: The Moderating Effects of Psychological and Relational Factors", Korean Association of Addiction Crime Revie. 2021, 11(1), 83-105, https://doi.org/10.26606/kaac.2021.11.1.5

[12] 2020 The Survey on Smartphone Overdependence https://www.nia.or.kr/site/nia_kor/ex/bbs/View.do?cbIdx=65914\&bc Idx $=23109 \&$ parentSeq $=23109$

(accessed on May 23 2021)
[13] The Definition of Smartphone Addiction https://www.kyci.or.kr/specialserv/specialserv06_1.asp

(accessed on May 7 2021)

[14] What is smartphone addiction?

http://www.gsiwill.or.kr/contents/holic/smart_holic.html (accessed on May 7 2021)

[15] Lim, J.Y. "The Mediation Effect Verification of Narcissistic Personality Traits and Schizophrenic Personality Traits on the Relationship between Smartphone Addiction and Relational Aggression of Middle School Girls", The Journal of the Korea Contents Association. 2016, 16(11), 199-210, http://dx.doi.org/10.5392/JKCA.2016.16.11.199

[16] Hwang, J.E. and Kim, J.H. "The Mediating Effect of Resilience on the Relationship among Smart Phone Addiction, Aggression, and School Adaptation of Adolescents", Korean Journal of Educational Therapist. 2016, 8(3), 369-384.

[17] Cho, C.B. "Smart-phone Addiction and Off-line Delinquency in Adolescence: Focused on the Mediating Effects of On-line Delinquency", Korean Journal of Social Welfare Research. 2017, 55, 317-345, https://doi.org/10.17997/SWRY.55.1.11.

[18] Seo, I.K. and Lee, Y.S. "Effects of Adolescents' Motivation for Use of Smart Phone on their Addiction to Smart Phone: Control Effect of Social Support”, Journal of Rehabilitation Psychology. 2016, 23(4), 857-875.

[19] Shin, H.N. and Jeong, S.H. "The Predictors of Children and Adolescents' Smartphone Addiction", Journal of Cyber Communication Academic Society. 2018, 35(3), 5-50.

[20] Jun, W.C. "An Analysis Study on Correlation Between Dual-income Family and Internet Addiction of Children", Asia-pacific Journal of Multimedia Services Convergent with Art, Humanities, and $\begin{array}{llll}\text { Sociology. } & 2016, & 6(4), & 81-88,\end{array}$ http://dx.doi.org/10.14257/AJMAHS.2016.04.04

[21] Jun, W.C. "An Analysis Study on Correlation of Internet Addiction and Smartphone Addiction of Teenagers", Proc. of 2015 2nd International Conference on Information Science and Security, December 14-16, 2015, 1-3, https://doi.org/10.1109/ICISSEC.2015.7370978

[22] 2019 The Survey on Smartphone Overdependence https://www.nia.or.kr/site/nia_kor/ex/bbs/View.do?cbIdx=65914\&bc Idx=21939\&parentSeq=21939

(accessed on May 23 2021)

[23] 2018 The Survey on Smartphone Overdependence

https://www.nia.or.kr/site/nia_kor/ex/bbs/View.do?cbIdx=65914\&bc Idx $=20876 \&$ parentSeq $=20876$

(accessed on May 23 2021)

[24] 2017 The Survey on Smartphone Overdependence

https://www.nia.or.kr/site/nia_kor/ex/bbs/View.do?cbIdx=65914\&bc Idx $=19592 \&$ parentSeq $=19592$

(accessed on May 232021 )

[25] Yu, Y.W., Song, Y.K., Yu, M.S., Jeon, J.Y. "Association between Physical Activity and Academic Problems due to Smartphone", Korean Society for the Study of Physical Education. 2018, 23(2), 103-113, http://dx.doi.org/10.15831/JKSSPE.2018.23.2.103 